\title{
Relationship between patient satisfaction with medical doctors and the use of traditional Korean medicine in Korea
}

\author{
Dongsu Kim ${ }^{1}$, Byungmook Lim² ${ }^{2 *}$ and Changhee Kim ${ }^{3}$
}

\begin{abstract}
Background: Satisfaction with medical doctor (MD) has been studied as a possible motivation for trying complementary medicine. This study aimed to explore the relationship between Korean outpatients' satisfaction with their MDs and their use of traditional Korean medicine (KM).

Methods: Data were drawn from the 2011 annual Korea Health Panel, a national representative sample. We analyzed the relationship between outpatients' use of KM and outpatients' satisfaction with MDs by using the responses of 9,753 outpatients, including 1,946 KM outpatients. The Andersen behavior model was applied to select the variables. The validity and reliability of the questionnaires were tested by Factor Analysis and Cronbach's alpha. Multiple logistic regression was used to evaluate five MD satisfaction indicators (patient's trust in MD, MD's careful listening, MD's sufficient explanation, MD's consultation time, and MD's respect for patient) and the overall satisfaction with the MD.

Results: There was no significant difference between the MD satisfaction of KM users and that of nonusers in any of the 5 indicators of MD satisfaction. When we controlled for all independent variables from the Anderson behavior model, however, the patients' overall dissatisfaction with MDs was associated with their use of KM (OR $=0.87,0.76-0.99)$. In addition, the more a patient was dissatisfied with the consultation time of their MD, the more they used KM $(\mathrm{OR}=0.82,072-0.94)$.
\end{abstract}

Conclusions: Patients who were dissatisfied with their MD were more likely to use KM; the main indicator affecting MD dissatisfaction was the relatively short time of MD consultations. This could be one reason why KM plays a complementary role with conventional medicine in Korea.

Keywords: Traditional Korean medicine, Doctor satisfaction, Anderson behavior model, Korea health panel, Western medicine

\section{Background}

Recently, interest in and use of complementary and alternative medicine (CAM) has increased worldwide [1-4]. With this heightened social interest, many studies have been conducted to determine who uses CAM, why they use it and how. A previous study revealed that CAM users are younger, more active, thinner, and more educated and earn more than non-CAM users [5]. Moreover, the use of CAM has increased due to the growth in the number of

\footnotetext{
* Correspondence: limb@pusan.ac.kr

2 Division of Humanities and Social Medicine, School of Korean Medicine,

Pusan National University, Yangsan, South Korea

Full list of author information is available at the end of the article
}

patients with chronic diseases $[3,4]$, its reduced side effects relative to western medicine (WM), and the expansion of insurance coverage for CAM [2].

Another important factor that influences CAM use is the health beliefs of patients and the general public. Among many aspects of health beliefs, we focused on satisfaction with MDs, which has been studied as a possible motivation for trying CAM [6]. According to previous studies of CAM users' beliefs pertaining to health care, CAM users have a holistic and independent health philosophy [7, 8], have incomplete trust in MDs [9], and have needs that have not been met by conventional medicine [6, 9-11]. However, previous studies have had limitations, such as not adjusting for the patient's disease 
[9], region $[6,11]$, and gender [10] and being too specific to represent the overall population and sociodemographic characteristics [7].

To investigate the influence of MD satisfaction on the use of CAM, we conducted a cross-sectional analysis with Korea Health Panel data surveying a national sample of the Korean population on the use and cost of health care services. Among the various CAM modalities, we focused on traditional Korean medicine (KM), which is a representative modality of CAM in Korea and has a competing relationship with WM in some areas [12, 13]. We identified people's characteristics and the factors of MD satisfaction associated with the use of KM.

\section{Methods}

\section{Data source}

We analyzed 2011 Korea Health Panel data collected jointly by the Korea Institute for Health and Social Affairs (KIHASA) and the Korean National Health Insurance Service. A Korea Health Panel sample was selected from the 2005 Korean Population and Housing Census data using region stratification variables. The data were initially collected from 7,009 households and 21,283 individuals in 2008, with 5,741 households and 17,035 individuals remaining in 2011. A detailed description of the Korea Health Panel was presented elsewhere [14, 15]. This study used public data from the Korea Health Panel that did not include any personal identification, and the survey conformed to local legislation and the Declaration of Helsinki. The data were provided by KIHASA with permission to use and analyze them.

\section{Sample selection}

We selected and analyzed individuals over 18 years old who used outpatient services in 2011. A total of 4,352 individuals under 18 years old in 2011 were excluded based on the age criterion. Outpatients were defined as individuals who used WM or KM more than once in 2011, and 2,376 persons who did not use outpatient services or who used only dental or maternity care services were excluded. The final number of subjects was 9,753, as 554 who either did not or could not answer the questionnaire were excluded (Fig. 1).

Among the final subjects, $\mathrm{KM}$ users were defined as those who used KM more than once in 2011; the subjects included 1,870 individuals who used WM and KM jointly and 76 who used KM only. The 7,807 individuals classified as KM nonusers were those who used outpatient services other than dental or maternity clinic services more than once and did not use KM in 2011.

\section{Model}

Andersen [16] suggested an initial behavioral model in which predisposing characteristics, enabling resources and needs influence the use of health services. He also noted that health beliefs (i.e., attitudes and values about

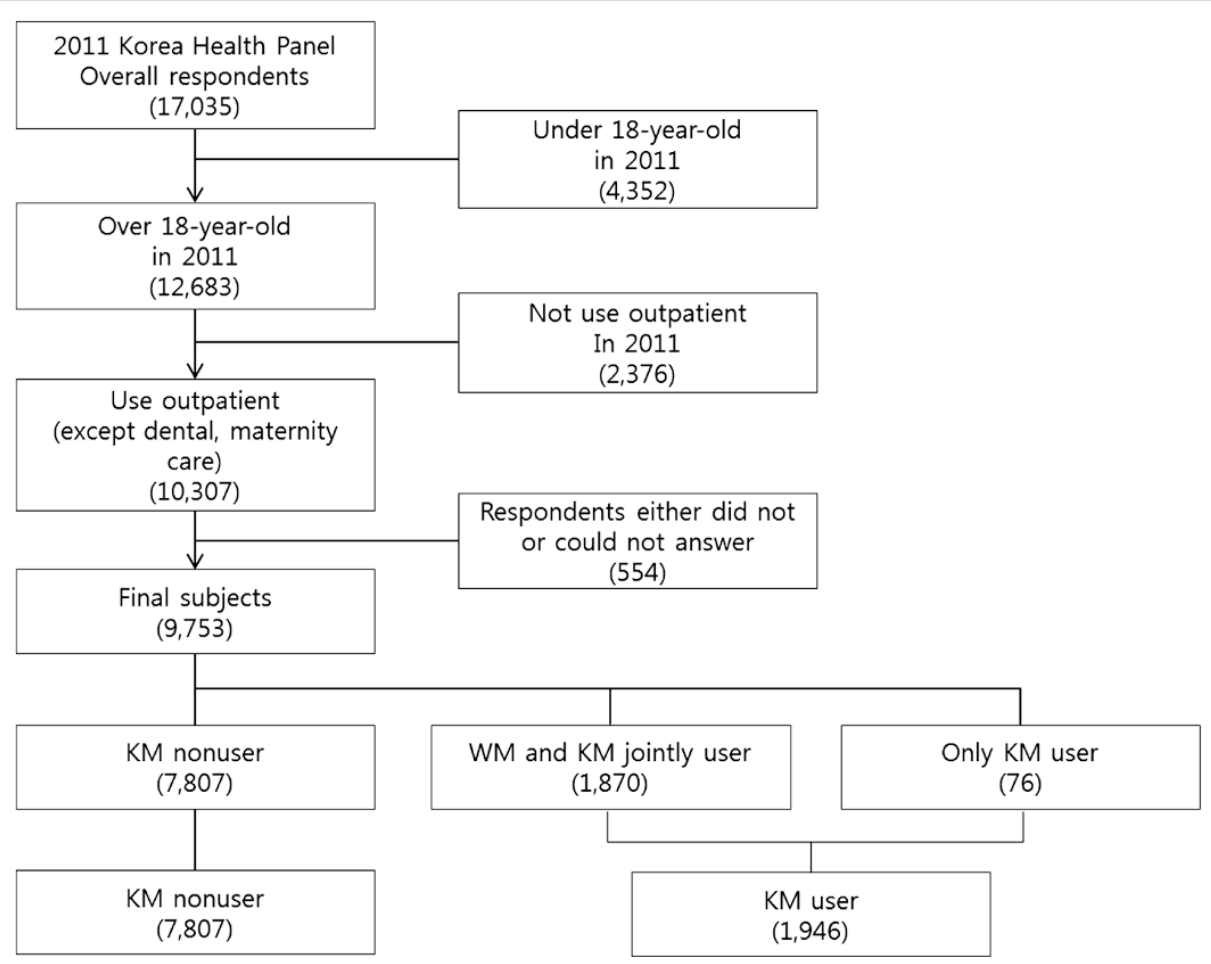

Fig. 1 Selection process of study subjects 
health and health services) affect the use of health services as predisposing characteristics [16]. According to Andersen's model, we included MD satisfaction with other health beliefs as independent variables, and we added predisposing characteristic variables, enabling resource variables, and needs variables as covariates that modify the use of KM.

\section{MD satisfaction}

Initially, the survey questionnaire contained 7 indicators with a 4-point Likert scale regarding MD satisfaction; 'trust in the MD,' 'MD's careful listening,' 'MD's sufficient explanation,' 'MD's consultation time, 'MD's respect for patient,' 'frequency of health care facility visits' and 'usefulness of screening'. We performed a factor analysis to examine the conceptual congruence of these 7 indicators, and, as a result, we excluded 2 indicators during the analysis; 'frequency of health care facility visits' and 'usefulness of screening' (Table 1). Then, we combined remaining 5 indicators into one factor. This factor showed good internal consistency, and Cronbach's alpha was 0.8591 . We additionally generated an "overall MD satisfaction" variable by using the mean value of the 5 indicators in this factor.

\section{Covariates}

In this study, the covariates comprised predisposing characteristics, enabling resources and needs that are known to have an effect on health care use in Andersen's behavior model. The predisposing characteristic variables are age, gender, education and residential area. The residential areas listed in the questionnaire included 16 Korean cities and provinces, but we condensed these to 5 areas (Seoul metropolitan area, Chungcheong-Gangwon, Yeongnam, Honam, and Jeju) in consideration of the cultural traits and geographic proximity of the residential areas.

Enabling resource variables included marital status, work status, household income and residential characteristics; residential characteristics were divided into urban and rural. Need variables were composed of the number of patients with and without chronic diseases, hypertension, diabetes, arthritis, and neoplasms; a subjective health status assessment; and quality of life. Among these variables, the quality-of-life variable was calculated by scores on the EQ-5D profile adjusted by a South Korean time trade-off value [17]. Subjective health status was surveyed with a 5-point Likert scale; the higher the score, the more negative one's perception of one's health.

\section{Analysis}

The chi-square test (categorical variables) and $t$-test (continuous variables) were used to examine differences in the use of KM according to MD satisfaction variables and covariates. Then, we entered covariates found to be significantly associated with CAM use in the univariate analysis into a multiple logistic regression model. The criterion for covariate entry was $p=0.2$. However, although all variables of MD satisfaction were $p>0.2$, we included them in the analysis. We then sequentially added the variables for 1) MD satisfaction; 2) predisposing factor; 3) enabling factor; and 4) need factor to the unadjusted model.

Each logistic regression analysis that was conducted included a goodness-of-fit test and c-statistic. In addition, we measured the multi-collinearity between the variables. All analyses were performed using Stata/IC, version 12.1 (Stata Corp, College Station, TX). Hypothesis testing was conducted using an alpha level of 0.05 .

\section{Results}

Among the 9,753 study subjects, 1,946 (20.0\%) used KM. 1,946 (20.0\%). The KM users consisted of 1,351 women $(23.6 \%), 628$ with an elementary school education $(25.7 \%), 898$ with non-economic activities (21.9\%), 590 in the bottom $25 \%$ of household income (24.0\%), 980 with more than three chronic diseases (28.6\%), 565 with hypertension (22.3\%), and 467 with arthritis (32.7\%). The KM users' mean age was 55.6, which was lower than that of non-users. The users' mean EQ-5D score

Table 1 Questionnaire on patients' satisfaction with their medical doctors

$\begin{array}{ll}\text { 1. Trust in the MD } & \text { Do you generally trust the MD you visited? } \\ \text { 2. MD's careful listening } & \text { (1) Strongly agree (2) Somewhat agree (3) Somewhat disagree (4) Strongly disagree } \\ & \text { Did the MD you visited listen attentively? } \\ \text { 3. MD's sufficient explanation } & \text { (1) Strongly agree (2) Somewhat agree (3) Somewhat disagree (4) Strongly disagree } \\ & \text { Did the MD you visited provided easy-to-understand medical explanations? } \\ \text { 4. MD's consultation time } & \text { (1) Strongly agree (2) Somewhat agree (3) Somewhat disagree (4) Strongly disagree } \\ & \text { Did the MD you visited allocate enough consultation time to meet your needs? } \\ \text { 5. MD's respect for the patient } & \text { (1) Strongly agree (2) Somewhat agree (3) Somewhat disagree (4) Strongly disagree } \\ & \text { Did the MD you visited respect what you said? } \\ & \text { (1) Strongly agree (2) Somewhat agree (3) Somewhat disagree (4) Strongly disagree }\end{array}$


was low (0.892), and their subjective health status was poor (2.836) (Table 2).

When we did not control for variables, there was no significant difference between the MD satisfaction of KM users and that of non-users in any of the 5 indicators. In addition, there was no statistically significant difference in the overall MD satisfaction derived from the mean of the 5 indicators (Table 3).

As a result of the logistic regression, however, when controlling for predisposing characteristic variables,

Table 2 Descriptive statistics and bivariate analysis for the demographics of users and nonusers of KM

\begin{tabular}{|c|c|c|c|c|c|c|}
\hline & & \multicolumn{2}{|c|}{ Nonusers } & \multicolumn{2}{|l|}{ Users } & \multirow[t]{2}{*}{$p$-value } \\
\hline & & $\bar{N}$ & $\%$ & $\bar{N}$ & $\%$ & \\
\hline \multicolumn{7}{|l|}{ Predisposing characteristic variables } \\
\hline \multirow[t]{2}{*}{ Gender } & Male & 3,423 & 85.19 & 595 & 14.81 & \multirow[t]{2}{*}{$<0.001$} \\
\hline & Female & 4,384 & 76.44 & 1,351 & 23.56 & \\
\hline Age (yrs) & mean $\pm S D$ & \multicolumn{2}{|c|}{$51.503 \pm 16.207$} & \multicolumn{2}{|c|}{$55.608 \pm 15.575$} & $<0.001$ \\
\hline \multirow[t]{3}{*}{ Education } & $\leq$ Elementary school & 1,815 & 74.29 & 628 & 25.71 & \multirow[t]{3}{*}{$<0.001$} \\
\hline & $\leq$ High school & 3,495 & 80.34 & 855 & 19.66 & \\
\hline & $>$ High school & 2,497 & 84.36 & 463 & 15.64 & \\
\hline \multirow[t]{5}{*}{ Region } & Seoul metropolitan area & 3,229 & 81.44 & 736 & 18.56 & \multirow[t]{5}{*}{0.003} \\
\hline & Chungcheong-Gangwon & 1,054 & 78.42 & 290 & 21.58 & \\
\hline & Yeongnam & 2,342 & 79.69 & 597 & 20.31 & \\
\hline & Honam & 976 & 77.40 & 285 & 22.60 & \\
\hline & Jeju & 206 & 84.43 & 38 & 15.57 & \\
\hline \multicolumn{7}{|l|}{ Enabling resource variables } \\
\hline \multirow[t]{2}{*}{ Spouse } & Yes & 5,945 & 80.45 & 1,445 & 19.55 & \multirow[t]{2}{*}{0.081} \\
\hline & No & 1,862 & 78.80 & 501 & 21.20 & \\
\hline \multirow[t]{3}{*}{ Work status } & Not employed & 3,208 & 78.13 & 898 & 21.87 & \multirow[t]{3}{*}{$<0.001$} \\
\hline & Employed & 2,880 & 82.07 & 629 & 17.93 & \\
\hline & Self-employed & 1,719 & 80.40 & 419 & 19.60 & \\
\hline \multirow[t]{4}{*}{ Household annual income low level (\%) } & $<25$ & 1,869 & 76.01 & 590 & 23.99 & \multirow[t]{4}{*}{$<0.001$} \\
\hline & $<50$ & 1,955 & 80.69 & 468 & 19.31 & \\
\hline & $<75$ & 2,012 & 82.70 & 421 & 17.30 & \\
\hline & $\geq 75$ & 1,971 & 80.84 & 467 & 19.16 & \\
\hline \multirow[t]{2}{*}{ Regional characteristic } & Rural & 3,390 & 80.09 & 843 & 19.91 & \multirow[t]{2}{*}{0.935} \\
\hline & Urban & 4,417 & 80.02 & 1,103 & 19.98 & \\
\hline \multicolumn{7}{|l|}{ Needs variables } \\
\hline \multirow[t]{3}{*}{ Chronic disease } & No & 2,485 & 86.62 & 384 & 13.38 & \multirow[t]{3}{*}{$<0.001$} \\
\hline & $<3$ & 2,878 & 83.18 & 582 & 16.82 & \\
\hline & $\geq 3$ & 2,444 & 71.38 & 980 & 28.62 & \\
\hline \multirow[t]{2}{*}{ Hypertension } & No & 5,837 & 80.87 & 1,381 & 19.13 & \multirow[t]{2}{*}{0.001} \\
\hline & Yes & 1,970 & 77.71 & 565 & 22.29 & \\
\hline Diabetes & No & 7,053 & 80.28 & 1,732 & 19.72 & 0.077 \\
\hline & Yes & 754 & 77.89 & 214 & 22.11 & \\
\hline Arthritis & No & 6,846 & 82.23 & 1,479 & 17.77 & $<0.001$ \\
\hline & Yes & 961 & 67.30 & 467 & 32.70 & \\
\hline Neoplasm & No & 7,363 & 80.36 & 1,800 & 19.64 & 0.003 \\
\hline & Yes & 444 & 75.25 & 146 & 24.75 & \\
\hline EQ-5D & mean \pm SD & & & & & $<0.001$ \\
\hline Subjective health condition & mean \pm SD & & & & & $<0.001$ \\
\hline
\end{tabular}


Table 3 Satisfaction with MDs for users and nonusers of KM

\begin{tabular}{|c|c|c|c|c|c|c|}
\hline & & \multicolumn{2}{|c|}{ Nonusers } & \multicolumn{2}{|l|}{ Users } & \multirow[t]{2}{*}{$p$-value } \\
\hline & & $N$ & $\%$ & $N$ & $\%$ & \\
\hline \multirow[t]{2}{*}{ Trust in the MD } & Dissatisfaction & 755 & 81.98 & 166 & 18.02 & \multirow[t]{2}{*}{0.124} \\
\hline & Satisfaction & 7,052 & 79.85 & 1,780 & 20.15 & \\
\hline \multirow[t]{2}{*}{ MD's careful listening } & Dissatisfaction & 731 & 81.86 & 162 & 18.14 & \multirow[t]{2}{*}{0.155} \\
\hline & Satisfaction & 7,076 & 79.86 & 1,784 & 20.14 & \\
\hline \multirow[t]{2}{*}{ MD's sufficient explanation } & Dissatisfaction & 852 & 80.53 & 206 & 19.47 & \multirow[t]{2}{*}{0.678} \\
\hline & Satisfaction & 6,955 & 79.99 & 1,740 & 20.01 & \\
\hline \multirow[t]{2}{*}{ MD's consultation time } & Dissatisfaction & 2,095 & 79.00 & 557 & 21.00 & \multirow[t]{2}{*}{0.113} \\
\hline & Satisfaction & 5,712 & 80.44 & 1,389 & 19.56 & \\
\hline \multirow[t]{2}{*}{ MD's respect for the patient } & Dissatisfaction & 931 & 79.10 & 246 & 20.90 & \multirow[t]{2}{*}{0.386} \\
\hline & Satisfaction & 6,876 & 80.18 & 1,700 & 19.82 & \\
\hline Overall MD satisfaction & mean $\pm S D$ & \multicolumn{2}{|c|}{$2.960 \pm 0.401$} & \multicolumn{2}{|c|}{$2.956 \pm 0.380$} & 0.670 \\
\hline
\end{tabular}

enabling resource variables and needs variables, the more people were dissatisfied with their doctor, the more they used KM $(\mathrm{OR}=0.87)$. Specifically, the more a patient was dissatisfied with the "consultation time of the MD", the more they used KM $(\mathrm{OR}=0.82)$, whereas "trust in the MD", "MD's careful listening", "MD's sufficient explanation" and "MD's respect for the patient" did not show a statistically significant influence on the use of KM (Table 4).

\section{Discussion}

There have been many previous studies on whether MD satisfaction influences the use of CAM, but the results varied. Downer [11] and Sirois [6] noted that CAM users showed a great deal of dissatisfaction with conventional medicine, whereas Eisenberg [18] and Astin [8] noted that the use of CAM was not influenced by dissatisfaction with conventional medicine or MDs. The studies noting that the use of CAM was associated with dissatisfaction with conventional medicine suggested that people think conventional medicine alone cannot help fight disease and is not helpful $[6,10,11]$, and the studies indicated that this distrust of treatment effectiveness was more important than the doctor-patient relationship or the patient's beliefs regarding health and medicine $[6,11]$. The British Medical Association's Board of Science and Education [19] also noted that the most significant reason for the success of CAM has been the failure of modern science and conventional medicine to treat incurable diseases.

It was difficult to verify directly how much the treatment effectiveness of conventional medicine related to

Table 4 Results from multivariate analysis for users and nonusers of KM

\begin{tabular}{lllll}
\hline & Unadjusted & +Predisposing variables & +Enabling variables & +Need variables \\
\hline Trust in the MD & $1.18(0.96-1.44)$ & $1.13(0.92-1.34)$ & $1.13(0.92-1.38)$ & $1.12(0.91-1.38)$ \\
MD's careful listening & $1.23(0.98-1.56)$ & $1.23(0.98-1.56)$ & $1.23(0.97-1.56)$ & $1.18(0.93-1.50)$ \\
MD's sufficient explanation & $1.04(0.85-1.27)$ & $1.04(0.85-1.27)$ & $1.03(0.84-1.27)$ & $1.06(0.86-1.30)$ \\
MD's consultation time & $0.88^{*}(0.77-1.00)$ & $0.82^{* *}(0.71-0.93)$ & $0.82^{* *}(0.72-0.93)$ & $0.82^{* *}(0.72-0.94)$ \\
MD's respect for the patient & $0.86(0.71-1.04)$ & $0.84(0.69-1.03)$ & $0.84(0.69-1.03)$ & $0.85(0.70-1.04)$ \\
Log likelihood & -4868.1342 & -4747.1273 & -4743.7057 & -4651.1695 \\
Goodness-of-fit test ( $p$-value) & 0.5478 & 0.1363 & 0.5438 & 0.4848 \\
c-Statistic & 0.5187 & 0.6170 & 0.6189 & 0.6513 \\
Mean VIF & 1.56 & 1.55 & 1.62 & 1.63 \\
Overall MD satisfaction & $0.97(0.86-1.10)$ & $0.88^{*}(0.77-1.00)$ & $0.88^{*}(0.77-1.00)$ & $0.87^{*}(0.76-0.99)$ \\
Log likelihood & -4873.956 & -4753.6 & -4749.9115 & -4655.9882 \\
Goodness-of-fit test $(p$-value) & 0.0223 & 0.4538 & 0.4323 & 0.4997 \\
c-Statistic & 0.5136 & 0.6143 & 0.6161 & 1.60 \\
Mean VIF & - & 1.48 & 0.6491
\end{tabular}

(unit: OR, $95 \%$ Conf. Interval)

*: $p<0.05$ **: $p<0.01$ 
dissatisfaction with MDs because we did not include perception of treatment effectiveness of conventional medicine as an explanatory variable. However, among the 5 indicators used for variables, "trust in the MD" could be considered the most relevant to treatment effectiveness, so we analyzed this variable. The level of "trust in the MD" did not affect the use of KM. Rather, KM users had a tendency to show higher trust in their doctor than KM non-users, although the difference was not statistically significant. This appears to be in agreement with the results of a previous study [18] indicating that most CAM users believe it is better to use both conventional medicine and CAM rather than to discard the treatments of conventional medicine. In other words, KM users use KM not as a substitute for conventional medicine but as a complementary and additional type of medicine. Choi [20] also reported that KM has a complementary relationship with conventional medicine.

We consider that "trust in the MD" is the most relevant indicator regarding the treatment effectiveness of conventional medicine, but Paltiel [9] explained that "trust in the MD" is relevant to authority rather than effectiveness. He also suggested that the reason for incomplete trust in the doctor is that patients try not to accept patriarchal and authoritative conventional medicine. Thus, we could allow that "trust in the MD" combined both trust in treatment effectiveness and factors such as intimacy, kindness, and faithfulness.

The results of our analysis revealed that the biggest reason for dissatisfaction with MDs was the lack of consultation time. Many international studies have reported that CAM doctors spend more time with their patients than do traditional MDs [18, 21-23]. In Korea, similar results were reported showing that an MD's average consultation time per patient was $2 \mathrm{~min}$ and 34 sec at clinics, whereas a KM doctor's consultation time was $3 \mathrm{~min}$ and $19 \mathrm{sec}$ at clinics [24]. In Korea, the number of MDs was 2.1 per 1,000 people, the lowest among OECD member countries (Avg. 3.2) [25]. The number of outpatient visits (per capita) was 14.3, which was the second highest among OECD countries (Avg. 6.9) [25]. This situation forces MDs to see more patients during a given time to gain more economic benefit; therefore, we could consider that complaints about insufficient consultation time make the use of $\mathrm{KM}$ more attractive.

This study reconfirms the results of a previous study [18] showing that patients used CAM not only to alleviate their dissatisfaction with conventional medicine but also to seek, explore, and experience benefits from both conventional and CAM therapies. Our study results were in contrast to those of another study [11] that showed that patients with severe disease used CAM to gratify psychological needs for medical service; our results showed that patients with severe disease were highly affected by psychological needs such as a doctor's respect, which is related to KM use. These findings indicate that patients who use KM do not abandon conventional medicine but demand more responsibility from the medical community as a broader distributor of health and medical services, and conventional medicine and CAM should be integrative partners in the health and medical fields to help improve patients' psychological health [18].

Our study has some limitations. First, we could not identify a causal relationship between the use of KM and variables known to be related to the use of KM by cross-sectional analysis. Second, the health beliefs influencing the use of health services include attitudes, values, and knowledge [16] about health and health services, but we only included variables regarding the doctor-patient relationship due to the limitations of the Korea Health Panel data. Finally, the term KM doctor is legally separate from MD. Some people, however, could not distinguish KM doctors from MDs because a KM doctor's legal status is very similar to a WM doctor's. Some respondents in the Korea Health Panel survey might have had similar confusion when they answered the questionnaire; this might have caused information bias.

Despite the limitations mentioned above, this study is the first attempt to address the relationship between MD satisfaction and the use of KM and provides reliable results by adjusting the variables of respondents' sociodemographic characteristics, which were categorized with Andersen's behavior model.

\section{Conclusions}

Patients who were dissatisfied with their MD were more likely to use $\mathrm{KM}$; the main indicator affecting MD dissatisfaction was the relatively short time of MD consultations. This could be one reason why KM plays a complementary role with conventional medicine in Korea.

\section{Abbreviations \\ KM: Traditional Korean medicine; CAM: Complementary and alternative medicine; MD: Western medicine doctor; WM: Western medicine; KHP: Korea health panel;} OR: Odds ratio.

\section{Competing interests}

The authors declare that they have no competing interests.

\section{Authors' contributions}

DK and BL participated in the study design, statistical analysis, interpretation, and writing of the article. CK participated in the interpretation, writing and editing of the article. All authors read and approved the final manuscript.

Authors' Information

Not Applicable. 


\section{Acknowledgments}

The authors would like to thank Dr. Jong-Min Woo for proof reading. This study was supported by the 'Research Policy and Strategy Planning Project' (Grant No. K15660) from the Korea Institute of Oriental Medicine (KIOM).

\section{Author details}

${ }^{1}$ Policy Division, Korea Institute of Oriental Medicine, Daejeon, South Korea. ${ }^{2}$ Division of Humanities and Social Medicine, School of Korean Medicine, Pusan National University, Yangsan, South Korea. ${ }^{3}$ Division of Longevity and Biofunctional Medicine, School of Korean Medicine, Pusan National University, Yangsan, South Korea. ${ }^{\sharp}$ \#316 School of Korean Medicine, Pusan National University, Gyeongnam 626-770, South Korea.

Received: 18 May 2015 Accepted: 25 September 2015

Published online: 14 October 2015

\section{References}

1. Can G, Erol O, Aydiner A, Topuz E. Quality of life and complementary and alternative medicine use among cancer patients in Turkey. Eur J Oncol Nurs. 2009;13(4):287-94.

2. Chen FP, Chen TJ, Kung YY, Chen YC, Chou LF, Chen FJ, et al. Use frequency of traditional Chinese medicine in Taiwan. BMC Health Serv Res. 2007;7:26.

3. Spencer JW, Jacobs JJ. Complementary and alternative medicine: an evidencebased approach. St Louis: Mosby; 2003.

4. Miriam SW, Kaptchuk TJ, Haramati A, Eisenberg DM. Complementary and alternative medical therapies: implications for medical education. Ann Intern Med. 2003;138:191-6.

5. Eisenberg DM, Davis RB, Ettner SL, Appel S, Wilkey S, Van Rompay M, et al. Trends in alternative medicine use in the United States, 1990-1997: results of a follow-up national survey. JAMA. 1998;280(18):1569-75.

6. Sirois FM. An investigation of the health beliefs and motivations of complementary medicine clients. Soc Sci Med. 2002;55(6:)1025-1037

7. Barnes PM, Nahin RL. Complementary and alternative medicine use among adults and children: United States, 2007. Natl Health Stat Rep. 2008;12:1-24.

8. Astin JA. Why patients use alternative medicine: results of a national study. JAMA. 1998;279(19):1548-53.

9. Paltiel O, Avitzour M, Peretz T, Cherny N, Kaduri L, Pfeffer RM, et al. Determinants of the use of complementary therapies by patients with cancer. J Clin Oncol. 2001;19(9):2439-48

10. Upchurch DM, Burke A, Dye C, Chyu L, Kusunoki Y, Greendale GA. A sociobehavioral model of acupuncture use, patterns, and satisfaction among women in the United States, 2002. Womens Health Issues. 2008;18:62-71.

11. Downer SM, Cody MM, McCluskey P, Wilson PD, Arnott SJ, Lister TA, et al. Pursuit and practice of complementary therapies by cancer patients receiving conventional treatment. BMJ. 1994;309:86-9.

12. Na SS. East Asian medicine in South Korea. Harvard Asia Quarterly. 2012;14(4):44-56.

13. Choi JH, Kang S, You CH, Kwon YD. The determinants of choosing traditional Korean medicine or conventional medicine: findings from the Korea health panel. Evid Based Complement Alternat Med. 2015;2015:147408. doi:10.1155/ 2015/147408. Epub 2015 Jun 25.

14. Korea health panel. [http://www.khp.re.kr/english/about_01.jsp]

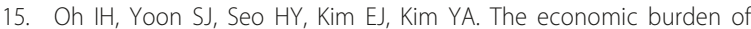
musculoskeletal disease in Korea: a cross sectional study. BMC Musculoskelet Disord. 2011;12:157. doi:10.1186/1471-2474-12-157.

16. Andersen RM. Revisiting the behavioral model and access to medical care: does it matter? J Health Soc Behav. 1995;36:1-10.

17. Lee YK, Nam HS, Chuang LH, Kim KY, Yang HK, Kwon IS, et al. South Korean time trade-off values for EQ-5D health states: modeling with observed values for 101 health states. Value Health. 2009;12(8):1187-93.

18. Eisenberg DM, Kessier RC, Rompay MI, Kapchuk TJ, Wilkey SA, Appel S, et al. Perceptions about complementary therapies relative to conventiona therapies among adults who use both: results from a national survey. Ann Intern Med. 2001;135(5):344-51.

19. BMA Board of science and education. Alternative therapy. London: BMA; 1986.

20. Choi B, Kim D, Yoo WK, Yun Y, Kwon YK, Lee SJ, et al. Identifying complementary and substitute relationships between Korean medicine and Western medicine using Korea health panel dataset. Kor J Oriental Preventive Medical Society. 2013;17(3):1-1.
21. Murray J, Shepherd S. Alternative or additional medicine? An exploratory study in general practice. SocSci Med. 1993;37:983-8.

22. Hentschel C, Kohnen R, Hauser G, Lindner M, Hahn EG, Ernst E. Complementary medicine today: patient decision for physician or magician? A comparative study of patients deciding in favour of alternative therapies. Eur J Phys Med Rehabil. 1996;6:144-50.

23. Cherkin DC, MacCornack FA. Patient evaluations of low back pain care from family physicians and chiropractors. West J Med. 1989;150:351-5.

24. Kim J. A comparative analysis of RBRVS for a doctor's consultation in western and oriental medicine. Kor J Oriental Preventive Medical Society. 2004;8(2):129-39.

25. OECD. OECD Health Data 2014. doi:10.1787/health-dataen. [http///mww.oecdilibrary.org/social-issues-migration-health/data/oecd-health-statistics_health-data-en]

\section{Submit your next manuscript to BioMed Central and take full advantage of:}

- Convenient online submission

- Thorough peer review

- No space constraints or color figure charges

- Immediate publication on acceptance

- Inclusion in PubMed, CAS, Scopus and Google Scholar

- Research which is freely available for redistribution 